\title{
Study on the Efficiency of Regional Innovation Resource Allocation in China
}

\author{
Jing Liu \\ Jiangxi Normal University Business College \\ Nanchang, China \\ Liujing32401@sohu.com
}

\author{
Yi Zhou \\ Jiangxi Normal University Business College \\ Nanchang, China
}

\begin{abstract}
The efficiency of regional innovation resource allocation reflects the ability of a region to use and integrate resources, which represents the overall function and efficiency of regional system, and determines the strength of regional capacity to a certain extent. As a developing country, China's regions are more in need of economic, rational and efficient allocation of limited resources, with limited financial and human resources, as much as possible for the output. On the basis of summarizing the research on the efficiency of regional innovation resource allocation, this paper analyzes the influencing factors of the efficiency and efficiency of regional innovation resource allocation, and finds that there are uneven distribution of resources in China's regional innovation resource allocation, dislocation of industrial structure, dislocation of main body, And then put forward the countermeasures to improve the efficiency of resource allocation in China.
\end{abstract}

Keywords-regional; innovative resource; allocation efficiency; local protectionism

\section{INTRODUCTION}

The efficiency of regional innovation resource allocation embodies the comprehensive ability of regional integration and utilization of innovative resources and the level of sustainable innovation and development. Resource allocation is about how to allocate and use different activities of the main body, field, time and space on the various types of resources, the overall goal is to make the overall economic and social benefits to achieve the best. In view of the great differences in the factor endowments of resources in China, it is very important to study the allocation of resources from the regional perspective and to compare and analyze the efficiency of the allocation of innovative resources in different regions [1].

\section{INFLUENCING FACTORS OF REGIONAL INNOVATION RESOURCE ALLOCATION EFFICIENCY IN CHINA}

\section{A. Subjective Factors}

Optimizing regional innovation The direct goal of resource allocation is to enhance regional innovation capacity, technological innovation, knowledge innovation and institutional innovation is the most common way of innovation. In the economic system, the main body of the three innovative ways is the enterprises, universities and scientific research institutions, the government, therefore, the three innovative main body is the main body of regional innovation resource allocation. The role of these subjects in the regional innovation resource allocation system is different, but it is mutual influence, interrelated and inseparable, therefore, constitute the regional innovation resource allocation main subsystem. The configuration of the main subsystem is an important part of the regional innovation resource allocation system. The synergies between the configuration entities in the subsystem will promote the transformation of the regional innovation resource allocation activities from the theoretical form to the realistic form, and effectively enhance the regional innovation resource allocation The ability and efficiency [2].

\section{B. Object Factors}

Resources are human beings that can be transformed into the source of social wealth, which is the material basis for human production. Innovative resources, is a non-natural resources or social resources, is the material conditions of innovation activities depend on, after the use of inputs can directly produce innovative results. Regardless of what kind of innovation activities, must invest a certain amount of innovative resources elements, through innovation activities directly produce knowledge and material form of innovation results. Compared with other economic resources, innovative resources have a large value-added, can produce far greater value than their own value, but the innovative resources with long-term performance from the innovation to the production and then to the final economic benefits, the need for a relative Longer processes, some of the innovative results can have a profound impact on the economy and society. According to the functions of participating in regional innovation activities, it can be divided into four categories: innovative human resources, innovative financial resources, innovative material resources and innovative information resources. These four types of resources are the object of regional innovation resources, Configure the subject of the subject. Regional innovation resource allocation object is the recipient of the configuration of the main behavior, including innovative human resources, innovative financial resources, innovative information resources and innovative material resources. In the process of the allocation of innovative resources, a single innovation resource is difficult to play an independent role, need to cooperate with other innovative resources, so the interaction between the innovative resources, mutual influence, 
together constitute the regional innovation resource allocation object subsystem.

\section{Carrier Factors}

Regional innovation resource allocation carrier elements are the support platform for innovation resource allocation main body to carry out innovation activities. Its main functions include: integration, coordination, guidance and catalysis and risk control and other four aspects. The integration function is to market the integration of innovative resources according to the needs of innovation activities. The coordination function is to promote the synergies between the innovation subjects [3], reduce the waste of redundant construction and innovation resources, and coordinate the process of solving the innovation resource allocation process And improve the ability and efficiency of regional innovation. The guidance and catalytic functions are mainly embodied in the innovation knowledge between the main body of the innovation resource allocation and the innovation of the resources and the " The exchange of information platform to guide the flow of innovative resources to the direction of market demand, while achieving the spillover effect of knowledge and technology to catalyze the innovation efficiency of the main innovation output and the market speed of innovation results; risk control function is mainly embodied in the formation of information release And exchange platforms that provide innovative activities for the innovation of resource mobilization in the internal and external environment, or by providing appropriate resources to reduce the risk of innovation in specific projects. At present, the common elements of regional innovation resource allocation include: technology market, incubation organization, financial institution and other innovative intermediary service institutions.

\section{Area Protection}

For the economic interests of their respective regions, the local government inevitably introduced local protection policies, so that state-owned enterprises and high profits and taxes enterprises are protected by preferential policies. The interests of the governments of their respective regions to promote the development of the region's market, the name of "the development of local economy" slogan, to maximize their own interests, to invisible policies or expressly set the form of maintenance of local enterprises policy. Among them, localism mainly manifested in the following three ways: First, the government forced intervention, so that consumption can only buy locally produced goods; Second, local governments to foreign goods in the form of tax restrictions on other areas of goods or resources; Third, Local enterprises, for foreign enterprises to limit. So that the local government in order to encourage local enterprises and restrictions on the resources of other provinces to promote the local economic development, such behavior will undoubtedly lead to regional market segmentation, resulting in the loss of the national economic rate and market failure, reducing the efficiency of regional innovation and resource allocation efficiency. It is a direct impact on the fairness of the market economy, open and hinder the operation of China's market mechanism [4].

\section{EXISTING PROBLEMS OF REGIONAL INNOVATION RESOURCE ALLOCATION EFFICIENCY IN CHINA}

\section{A. Uneven Allocation of Resources}

As the socio-economic development of China's various regions show obvious characteristics of regional differences, according to the three major economic zones divided into the eastern region, due to better social and economic conditions, the scale of investment and investment intensity of resources, pay more attention to scientific and technological achievements Of the transformation and application, the allocation of resources is more significant. In recent years, while maintaining stable development in the eastern region, China has also focused on strengthening the rise of the central and western regions, invested a lot of manpower and material resources, the focus of resource allocation and configuration has improved, so that the central and western provinces and autonomous regions of the resource allocation Efficiency has improved. In the central region, except for Jiangxi and Shanxi, the backwardness of economic development has resulted in the allocation of resources behind the central provinces, and the efficiency of the other provinces is in the middle and upper reaches. The efficiency of resource allocation in the western provinces and autonomous regions is relatively poor. Some regional exceptions, such as Shaanxi and Sichuan, are mainly due to the fact that the military and financial enterprises, which are arranged in the third-line construction period, are better and have a strong resource allocation level, But because of the large population [5], become the main factor restricting its development. Most provinces in western China have extremely rich resources, but science and technology can not meet the mining requirements, it is difficult to use resources. For the west, the eastern provinces have a clear geographical advantage, not only rich in resources, but also has convenient transport conditions, the most important is the eastern region provinces have very sensitive business information. These are sufficient to prove that the original resource endowments, science and technology and economic fundamentals have a profound impact on resource allocation.

\section{B. Industrial Structure Disorder}

China has been positioning the Midwest as an energy and raw material base, making these areas of the industrial chain starting point is relatively low. Because science and technology are also the factors that affect the efficiency of resource allocation, the low level of science and technology in the central and western regions makes the resource consumption too large, and the evolution of the overall economic structure is relatively small. As China's economy continues to grow, the resources of the Midwest are overconsumed. Coupled with the technical level behind, resulting in waste of resource costs, the western resources are drying up, the phenomenon of resource mismatch is also more serious. Even if China's increased support for the central and western regions, but limited to the slow pace of its market system evolution, science and technology replacement costs are too high. China is in development, it is difficult to put a lot of manpower and material resources into the traditional industries, extending the local industrial chain. Can only let its development, but also with the coastal areas of technology, 
talent, industry chain and other advantages, the state also acquiesced in its allocation of resources in the pattern of the central and western regions. This will make the eastern and western industrial structure differentiation becomes more obvious, but also caused the allocation of resources, "East high west low" state. The mismatch of the traditional elements of our country creates a gap between the actual output and the potential output. Especially in the economic development of waste of resources and configuration unreasonable circumstances continue to use. Making China's resources mismatch, directly in the industry and the industry within the regional industrial structure convergence, but also hindered the free flow of factors of production.

\section{The Main Character Misplaced}

University is the creator and provider of knowledge and talent, business is the main body of technological innovation, the government is the organization coordinator. But at present, most of China's innovative resources in the governmentowned scientific research institutions and universities, enterprises lack their own innovative personnel and basic scientific research equipment. The consequences of this division of labor and cooperation mechanism are: lack of innovation resources, lack of interest in innovation activities, lack of competitiveness of the products; universities and scientific research institutions because of the lack of market sensitivity caused by the process of technological industrialization is difficult to achieve; To directly participate in the allocation of innovative resources and command, leading to technology and economic problems out of touch difficult to crack. Enterprises need the technical results and can not find a suitable supplier, enterprise product development problems encountered can not find the right science and technology personnel to solve, technology and economic problems are more serious. Long-term business difficult to become the main market $\mathrm{R} \& \mathrm{D}$ innovation, and universities and research institutes, although the results have been idle, resulting in a large number of innovative resources waste. Which makes it difficult for enterprises to rationally optimize the allocation of resources.

\section{Government is not Effective}

The key to resolving the short-term difficulties of the new economy is that the decisive role of market allocation is not played and the government's intervention in the market economy. The repeated implementation of local government local protection policy not only broke the strategy of market integration in our country, but also seriously hindered the new economic market construction. Government regulation of market vitality and elements of the optimal allocation of the system for the evolution of the market is a great constraint. Market reform is always faster than the reform of government departments, how to adapt to the market, play the price mechanism, supply and demand mechanism, competition mechanism and improve the market supervision system plays a decisive role in the optimal allocation of resources, the government how their attitude is new Under normal market segmentation for the construction of a major determinant of market economy. Market segmentation makes the government still play the role of "idle hands", too much intervention on the local economy, local enterprises to protect too much, companies rely heavily on local government protection, weaken the enterprise market competitiveness, but also easy to breed Rent ", hinder the market to play the necessary resource allocation function.

\section{PROMOTION STRATEGY OF REGIONAL INNOVATION RESOURCE ALLOCATION EFFICIENCY IN CHINA}

\section{A. To Promote the Main Collaborative Development}

China should improve the capacity of regional innovation resources allocation, making innovation investment can be better transformed into innovative output, to increase the economic benefits of innovation activities. We should strengthen the cooperation between enterprises, research institutions and institutions of higher learning, enterprises can use the university and research institutions of this window, with the universities and research institutions in the innovation activities of the exchange of cooperation to complete the product from research and development to put into use The process of creating economic benefits, and promote the development of economic level. Based on the impact of different innovation on the allocation of innovative resources to the role of different innovation into the main investment in the allocation of resources have a greater impact on the ability of a reasonable structure of the industry can make more efficient use of innovative resources. At present, China should speed up the establishment of enterprises as the main body, the combination of production and research innovation system, strengthen the enterprise's innovation ability, improve the research institutions and research institutions $R$ \& $D$ investment, making the main allocation of resources, play a role The And regional innovation resource allocation system is a complex system to guide the regional innovation resource allocation system to the more advanced orderly evolution needs to be done: First, to promote the coordination between the main body of the system. University is not only the creator of scientific knowledge and technology, but also the realization of the "technology transfer" and "entrepreneurial" function, the government is the university and scientific research institutions to technology transfer to the promoters and coordinators; industry enterprises and Universities and scientific research institutions to absorb the most cutting-edge science and technology for new product development. Secondly, we should keep the resources of the regional innovation resource allocation system effectively and improve the adaptability of the relevant government policies so as to reduce the resources of the regional innovation resource allocation system. Finally, strengthen the enterprise in the innovative resource allocation system in the main position, cultivate key technologies with new enterprises to support small and medium enterprises innovation activities to promote the continuous innovation and transformation of large enterprises [6]. 


\section{B. To Enhance the Efficiency of Guest Use}

Regional innovation resource allocation optimization from the object to start, that is, optimize the regional innovation resource allocation of input and output resources. Direct input of human resources, material and financial resources is the most important factor affecting the allocation of regional innovation resources. First of all should be rational allocation of $\mathrm{R} \& \mathrm{D}$ funding and staff input, not only to increase investment in research and development of financial resources, but also to expand the total amount of regional $\mathrm{R} \& \mathrm{D}$ personnel; the provincial government departments should be rational allocation of basic research, applied research and experimental development of the expenditure ratio, To study more funding support; to build a multi-faceted R \& D funding channels for enterprises, universities and research institutions to provide more financing platform to foster capital markets, the establishment of venture capital funds. Second, we should improve the capacity and efficiency of regional innovation resource allocation. Taking into account the strength and potential of fostering provincial resource allocation, and realizing the sustainable development of innovative resource allocation in each province. Finally, to strengthen the regional innovation resource allocation system of talent construction, regional innovation is the core of resource allocation system upgrade. Specifically, including two elements: to cultivate a cross-disciplinary and comprehensive background of the talent, the reform of university education system, corporate rotation and the introduction of complex background talent; to strengthen the training and the introduction of scarce talent, such as a new generation of information technology, New materials, high-end manufacturing, fashion creativity, new energy and energy saving and environmental protection, new energy vehicles, artificial intelligence and other specialized personnel training and introduction; encourage colleges and universities and foreign well-known universities to jointly run high-level and high-level technical personnel ; Local government to go out to introduce high-tech, high-level talent.

\section{To Accelerate the Carrier Platform Interaction}

Scientific and technological progress environment has a positive effect on regional resource allocation efficiency. It can be seen that the function of the carrier in the system is indispensable. The carrier has created a good environment for resource allocation in the regional innovation resource allocation, which accelerates the flow and interaction of elements in the system. Therefore, we want to improve the efficiency of regional innovation resource allocation, we must improve the provincial area of innovative resource allocation environment. Specifically, the main aspects include the following three aspects: First, improve the protection of intellectual property rights and innovation results transformation mechanism. Designing a system of intellectual property protection is the need to balance good incentives and restrictive effects and to design different systems for different industries and technologies. Optimize the transformation of intellectual property rights mechanism, the establishment of a unified technology transfer agencies, separate from the university technology transfer matters. Second, to build a variety of forms of innovative resource allocation service platform, such as technology trading market, business incubator and so on. Finally, with the help of fiscal and taxation policies to optimize regional resource allocation. Clear the role of the government in the different stages of the development of regional innovation resource allocation system, namely, cited persons, guarantors and logistics service providers.

\section{Breaking the Local Protectionism}

From the current form of our country, the government departments must be linked up and down, comprehensive norms. To monitor whether the local government in accordance with China's strategic point of view, there is no compliance with laws and regulations and the unified introduction of the national market mechanism of the policy. But also to clarify the local local state-owned enterprises and high profits and taxes tax incentives. Reward and punishment, abolish the impact of fair market competition or illegal policies, the complete elimination of local protectionist policies. Standardize the government to pay tax or non-tax revenue linked to the fiscal expenditure preferential policies to establish a sound long-term management mechanism.

\section{SUMMARY}

Since the reform and opening up, the market economy to the market, and government behavior led the evolution of this process. The government began to focus on the pursuit of maximization of interests, each region for their respective regional economic development has developed a series of local protection policies. And these policies for a short time to bring rapid economic development around the market system to provide a lot of financial support. Huge profits to China's economic construction to raise a lot of money, the Government vigorously implement the goal of maximizing the interests of the policy. In the long run, this will eventually bring difficulties to China's resource allocation. Based on this, the government should put the decisive position of the market, in the combination of the main body, the object, the carrier of a reasonable and optimal allocation, to break the local protectionism for China's long-term development of regional economy to provide protection.

\section{REFERENCES}

[1] S. H. Wei, G.S. Wu . Study on the Efficiency of Regional Science and Technology Resource Allocation .J. Scientific research, vol. 23, pp. 467473, 2005.

[2] X. R. Zhangi. Research on the Efficiency of Regional Science and Technology Resource Allocation in China .J. Industrial Technology Economy, vol. 28, pp. 116-118, 2008.

[3] F. Fan, D. B. Du. Regional science and technology resource allocation efficiency and comparative advantage analysis .J. Science Research, vol. 30, pp. 1198-1205, 2012.

[4] Y. J. Li, C.Z. Wang. Comparative Analysis of Resource Allocation Efficiency - A Case Study of China's Regional Higher Education Resources. J. Soft Science, vol. 28, pp. 22-26, 2014.

[5] F. Fan, J.Q. Zhang .Study on Spatial Spillover Effect of Regional Science and Technology Resource Allocation under Environmental Constraints .J. Urbanization and Regional Development, vol. 4, pp. 7180, 2016.

[6] W. Dai, X .F. Zhang. Research on Measurement of Financial Resources Allocation Efficiency Based on New Perspective. J. Soft Science, vol. 30, pp. 52-60, 2016. 